\title{
DISCURSOS E SENTIDOS DA PARTICIPAÇÃO POPULAR EM UM CENTRO DE SAÚDE DE BELO HORIZONTE
}

\author{
1-Paula Fernandes Furbino Bretas \\ Mestranda em Administração pela Universidade Federal de Minas Gerais (UFMG), Brasil. \\ paulaffb@gmail.com \\ http://lattes.cnpq.br/46376873874333353

\section{2-Luiz Alex Silva Saraiva} \\ Doutor em Administração pela Universidade Federal de Minas Gerais (UFMG), Brasil. \\ Professor do Centro de Pós-Graduação e Pesquisas em Administração da Universidade Federal de Minas Gerais (UFMG), \\ Brasil. \\ saraiva@face.ufmg.br \\ http://lattes.cnpq.br/8812184151373749
}

\author{
Diego Maganhotto Coraiola - Editor Geral \\ Editor responsável pela submissão: \\ Tania Margarete Mezzomo Keinert. \\ Artigo analisado via processo de revisão duplo cego (Double-blind). \\ Recebido em: 18/01/2014 \\ Aprovado em: 08/05/2014 \\ última Alteração: 18/04/2014
}

* Contato Principal: Av. Antonio Carlos, 6627, Pampulha, Belo Horizonte-MG, Brasil. CEP: 31270-901. 


\title{
DISCURSOS E SENTIDOS DA PARTICIPAÇÃO POPULAR EM UM CENTRO DE SAÚDE DE BELO HORIZONTE
}

\section{Resumo}

O objetivo neste artigo é identificar quais e como os sentidos sobre a participação popular são construídos por diferentes atores sociais relacionados a um centro de saúde de Belo Horizonte. Desde 1988, a temática da participação popular vem ganhando espaço de debate nas políticas públicas. Contudo, alguns autores questionam se essa participação ocorre como forma de discussão e deliberação, ou se apenas é utilizada como fachada para apresentação de propostas já concebidas pelos administradores dos órgãos públicos. Os instrumentos de coleta utilizados foram entrevistas semi-estruturadas e grupo focal, tendo sido os dados analisados à luz da análise crítica de discurso. As conclusões sugerem que os diferentes sentidos atribuídos à participação popular dirigem aos gestores desafios relacionados a lidar com distintas expectativas no cotidiano do centro de saúde.

Palavras-chave

Discursos. Sentidos. Participação popular. Centros de saúde. Belo Horizonte.

\section{DISCOURSES AND SENSES OF POPULAR PARTICIPATION IN A HEALTH CENTER FROM BELO HORIZONTE}

\begin{abstract}
Our goal in this paper is to identify what and how senses of popular participation are built by different social actor related to a health center of Belo Horizonte. Since 1988, popular participation theme has been developed and gaining space in public policy debate. However, some authors argue if this participation occurs as a way of discussion and deliberation or if is just used as a fachade to presentation of proposals already conceived by public managers. Collect data tools used were semi structured interviews and focus group. Data were analyzed through critical discourse analysis. Conclusions suggest that different senses related to popular participation challenge public managers to deal, daily, with different expectations at health center.
\end{abstract}

\section{Keywords}

Discourses. Senses. Popular participation. Health centers. Belo Horizonte. 


\section{Introdução}

A partir da Constituição Federal de 1988, a temática da participação popular vem ganhando espaço de debate na administração e nas políticas públicas. A gestão da saúde, por exemplo, passou a ser organizada de acordo com as diretrizes de: (1) descentralização, com direção única em cada esfera de governo; (2) atendimento integral, com prioridade para as atividades preventivas, sem prejuízo dos serviços assistenciais; e (3) participação da comunidade (Brasil, 2007). Neste artigo, será dada maior atenção à terceira diretriz.

Para Vasquez et al. (2003), a participação da sociedade na gestão das políticas públicas foi considerada como diretriz, quando da criação do Sistema Único de Saúde - SUS. Nessa nova concepção, a população estaria convocada a participar, de forma integrada, das deliberações do sistema público de saúde. Com o objetivo de criar espaços institucionais para a participação da sociedade, foram criados os conselhos por meio das leis complementares que regulamentam os artigos constitucionais da saúde. A finalidade desses organismos era "dar concretude ao direito constitucional à participação, entendida, assim, como a intervenção efetiva da sociedade na formulação, implementação e controle da política pública" (Cunha \& Pinheiro, 2009, p. 146).

Além dos conselhos, Vasquez et al. (2003) também ressaltam a criação de conferências e outros espaços institucionalizados que ampliaram a possibilidade de participação da população. Segundo Oliveira (2004, p. 65), "o desafio hoje é o de conhecer as dinâmicas interacionais dos conselhos, para apontar a ocorrência ou não da comunicação dialógica e, não ocorrendo, quais os prejuízos que traz para o processo de controle público e participação popular". Acredita-se que este estudo poderá contribuir para o entendimento dessa dinâmica interacional a partir dos discursos e sentidos construídos da participação popular em um caso empírico.

Discursos e sentidos aparecem no plural, uma vez que existe uma discussão sobre o entendimento do conceito de participação popular e a sua prática. Isto é, os conceitos não possuem um único sentido possível. Alguns autores (Vizeu \& Bin, 2008; Rosemberg, 2009) questionam, por exemplo, se essa participação ocorre como forma de discussão e deliberação ou se apenas é utilizada como fachada para apresentação de propostas já concebidas pelos administradores dos órgãos públicos.

Portanto, percebe-se que, para o conceito de participação popular, são produzidos e compartilhados vários sentidos (Weick, Sutcliffe, \& Obstfeld, 2005), caracterizando a construção social de realidades por meio dos discursos (Boje, Oswick, \& Ford, 2004). Esses sentidos não são aleatórios, já que o discurso expressa a compreensão de eventos sociais (Van Dijk, 1985) e orienta a ação (Weick, Sutcliffe, \& Obstfeld, 2005). Além de relatar e descrever, discurso também é prática social (Fairclough, 2001), pois pode-se criá-lo com a linguagem (Boje, Oswick, \& Ford, 2004). Isto é, a linguagem constitui um modo de ação e se relaciona com o social de forma dialética, sendo por ele moldada e também o moldando (Fairclough, 2001, 2010). Boje, Oswick e Ford (2004) argumentam que a inserção em um ponto de vista precede a criação de modo que se permite conhecer a realidade e orientar as ações. Percebendo os discursos como múltiplos, a constatação desses autores, que fundamenta este artigo, aponta como desafio de pesquisa o conhecimento e o desenho da relação entre discursos oficiais e marginalizados nas organizações situados nos contextos social, histórico e econômico.

Para compreender esse processo, este artigo se valeu de uma pesquisa descritiva, qualitativa. A unidade de análise foi grupal, analisando-se a Comissão Local de Saúde e os gestores que se relacionam com o objeto de estudo, o Centro de Saúde São Paulo, localizado na cidade de Belo Horizonte. Os instrumentos de coleta utilizados foram entrevistas semiestruturadas com cinco gestores públicos e um grupo focal com membros da comissão, cujos dados foram analisados à luz da análise de discurso crítica enquanto base teórico-metodológica (Fairclough, 2001).

O artigo está estruturado em cinco partes, na sequência desta introdução. Apresenta-se, o referencial teórico que visa discutir as ideias de produção de sentidos e construção social da realidade, de discurso como prática social e da produção de sentidos sobre participação popular. Em seguida, apresentam-se a metodologia e a análise dos dados obtidos a partir das entrevistas e do grupo focal. E, por fim, na quinta e última parte, serão tecidas as considerações finais.

\section{A Produção De Sentidos e a Construção Social Da Realidade}

Que sentido os indivíduos constroem, como o fazem e por que são questões centrais às quais o sensemaking vem tentar responder (Weick, 1995; Vieira \& Fonseca, 2009). Diante disso, os estudos organizacionais no Brasil utilizaram o sensemaking sob diversas orientações, tendo a construção de sentido como ponto em comum. Pensando que os sistemas de controle das organizações não são infalíveis, estando elas sujeitas a eventos inesperados, é interessante perceber que algumas organizações aprenderam a lidar com o inesperado, como as de alta confiabilidade. Companhias de energia elétrica, de energia nuclear, setores de emergência de hospitais, torres de controle aéreo, times de bombeiros são alguns exemplos dessas organizações que precisaram compreender certos fenômenos inesperados para a tomada de decisão (Borges, 2010).

Czarniawska (2005) nomeia gestão "consciente" quando se sabe das necessidades de correções em curso, sendo por si só um processo limitado. Contudo, existem ainda outros exemplos de uso do sensemaking na administração, como ferramenta estratégica para o desenvolvimento de redes de relacionamento de negócios (Vieira \& Fonseca, 2009), como possibilidade de ampliação do olhar sobre as comunidades virtuais no 
contexto organizacional (Schroeder, 2006), como variável identificada no processo strategizing (Montenegro \& Bulgacov, 2009) e, ainda, como ferramenta para considerar os aspectos culturais na aprendizagem (Maravalhas, 2010). Mas, o que é o sensemaking?

Vieira e Fonseca (2009, p. 2) resumem sensemaking “como uma atividade que o ator organizacional realiza de observação, interpretação e compreensão do mundo exterior, inferindo-Ihe sentidos lógicos advindos do uso de esquemas anteriores". Weick, Sutcliffe e Obstfeld (2005) o definem como um significativo processo de organizar, de desenvolver imagens do que as pessoas estão fazendo. A partir desse processo, o sujeito confere sentido do que está ao seu redor na organização, a todo momento, para que as suas ações se tornem possíveis (Montenegro \& Bulgacov, 2009). Quando o mundo é percebido diferente do esperado ou quando não há maneiras óbvias para envolver o mundo, o sujeito busca ordená-lo com plausibilidade.

Como um sistema de trocas permanentes, existem inputs ambíguos, outputs com sentido, resultando em um mundo ordenado para aquele indivíduo perante aquela situação (Weick, Sutcliffe, \& Obstfeld, 2005). Assim, o sensemaking é um processo no qual se busca compreender um problema, com base em experiências anteriores e interação com o grupo, de forma a encontrar uma decisão possível (Borges, 2010). E como isso acontece? O processo de sensemaking, cuja ideia apropria processos da evolução para a teoria organizacional (Borges, 2010), pode ser representado pela figura 1.

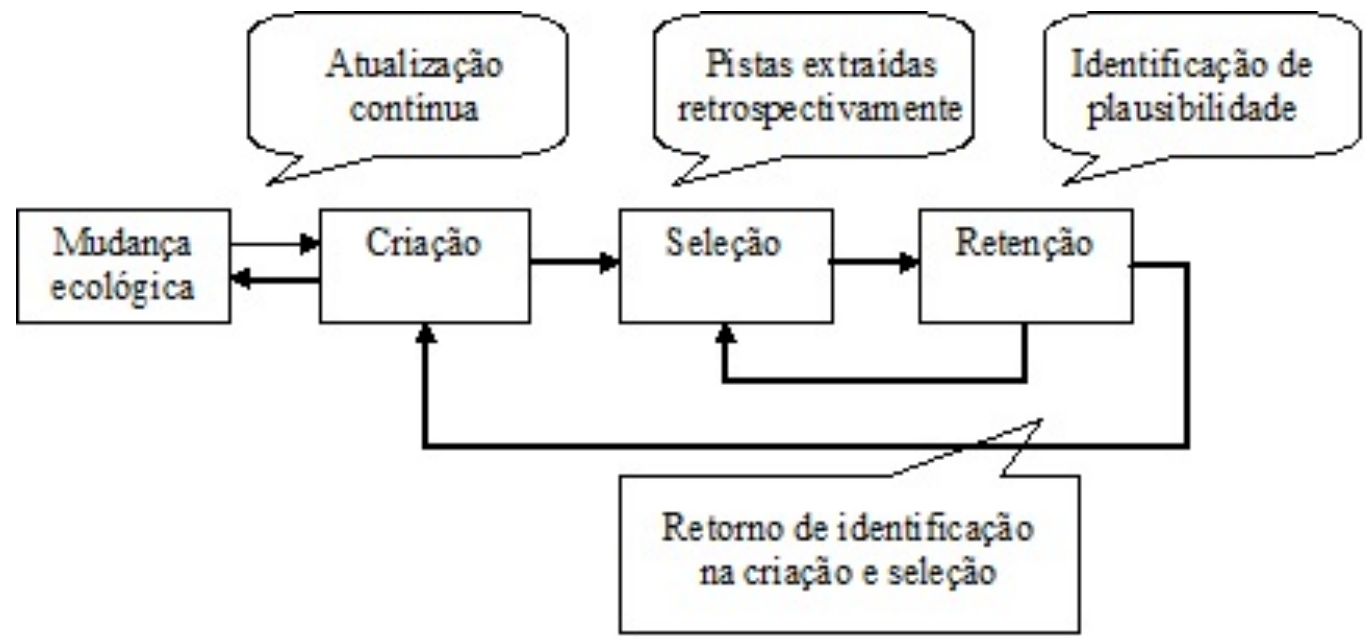

Figura 1. Processos de sensemaking nas organizações

Fonte: Weick, Sutcliffe e Obstfeld (2005).

Analisando a figura 1, percebe-se que a mudança tem um papel primordial, pois é ela que desestabiliza o sistema e causa a desordem. A gênese do sensemaking está em uma ambiguidade perturbadora, pois ela busca organizar fluxos. Algo vem a ser um evento para o sujeito quando ele questiona, levando o evento à existência e tentando trazer sentido para orientar sua ação, criando o que não existia antes (Vieira \& Fonseca, 2009). Portanto, a construção de sentido também depende da percepção da mudança, do caos. É guiada por modelos mentais adquiridos ao longo da vida, buscando interpretar e dar nomes aos eventos desconhecidos. Contudo, é interessante ressaltar que sensemaking e interpretação não são sinônimos, sendo aquele mais abrangente do que este. Enquanto o primeiro preocupa-se com o como, o segundo direciona-se ao o que (Montenegro \& Bulgacov, 2009).

O processo de criação é alimentado tanto pela retenção quanto pela mudança, conforme identificado pelas setas na Figura 1. Há uma escolha de experiências, de eventos significativos. A partir dessa atenção dada, reduz-se a ambiguidade, mas não se consegue afastá-la totalmente, já que o sentido na criação está mais ligado ao indivíduo, enquanto que no processo de seleção, está ligado à coletividade.

Após esse ato constitutivo do processo de criação, vem a seleção, cuja função é buscar referências no passado e também emergir de presunções sobre o futuro, havendo uma mistura entre retrospectiva e perspectiva. Contudo, essa não é uma busca individual, mas coletiva. Para Borges (2010, p. 17), “a função do processo de seleção é separar a maior parte das produções ambíguas e torná-las mais unívocas e ordenadas na medida do possível". Para tanto, é necessário que os indivíduos se perguntem o motivo pelo qual fazem aquilo e quais as consequências para o sistema, tendo em vista que ações egoístas podem destruir a coletividade (Borges, 2010).

Na medida em que o ciclo se repete e as mesmas interpretações são escolhidas, certas informações são retidas para aquela dada situação. Entretanto, vale frisar que fala e ação são ciclos mais do que sequências lineares, podendo a ação estar certa em um momento, e errada em outro, cuja significação é dada pela fala comunicação (Weick, Sutcliffe, \& Obstfeld, 2005). Essa ambiguidade, a qual se tenta diminuir a cada passo no processo do sensemaking, possui como fontes o processo de seleção, em virtude da coletividade, e a contradição entre conteúdos mais novos e mais antigos que foram retidos. A ambiguidade também pode ser considerada como o excesso de sentidos da informação (Borges, 2010). 
Portanto, com essa constante reorganização interna de conteúdos, percebe-se a construção de sentido como social e sistêmica, envolvendo diversos atores interdependentes simultaneamente, e tem como ponto culminante a articulação das construções de sentidos que pode ser feita por meio da comunicação (Weick, Sutcliffe, \& Obstfeld, 2005).

O sensemaking (Weick, 1995) também pode ser caracterizado por sete propriedades possíveis de se evidenciar em um evento que tenha oportunidade de criação de sentido organizacional (Borges, 2010), conforme Quadro 1.

\begin{tabular}{|l|l|}
\hline 1. Identidade & $\begin{array}{l}\text { Na relação com o outro que se constroi a identidade projetando-as no ambiente e observando as } \\
\text { consequências. Mesmo em processos mentais internos, o indivíduo leva em consideração a situação } \\
\text { em que se encontra, seu contexto, sendo atividade contingencial aos seus pares; }\end{array}$ \\
\hline 2. Retrospecto & Dá atenção ao que já ocorreu diretamente relacionado à memória; \\
\hline $\begin{array}{l}\text { 3. Promulgação/ } \\
\text { decretos }\end{array}$ & $\begin{array}{l}\text { Representa ambientes sensíveis, não existindo ambiente monolítico. Há uma relação dialética em que } \\
\text { as pessoas criam seus ambientes e são criadas por eles; }\end{array}$ \\
\hline 4. Contato social & $\begin{array}{l}\text { Considera a influência da socialização. A conduta individual é contingente com a conduta de outros } \\
\text { indivíduos }\end{array}$ \\
\hline $\begin{array}{l}\text { 5. Eventos em } \\
\text { processo }\end{array}$ & $\begin{array}{l}\text { É dinâmico, pois envolve um processo contínuo em que não há inícios nem fins. Contudo, Czarniawska } \\
\text { (2005) ressalta que há rotinas, estereótipos, ideias recebidas e verdades herdadas também na } \\
\text { construção de sentido. Mesmo que o processo se caracterize pela continuidade, a autora afirma que } \\
\text { nem sempre ele é intenso e que a atividade de construção de sentido aumenta de acordo com rupturas } \\
\text { e descontinuidades, choques e interrupções, ou seja, com as mudanças e ambiguidades crescentes; }\end{array}$ \\
\hline 6. Pistas & $\begin{array}{l}\text { É focado em e por dicas extraídas/ informações indiretas, situações nas quais sujeitos extraem de } \\
\text { estruturas familiares e simples alguns indícios a partir dos quais se pode desenvolver sentidos mais } \\
\text { amplos sobre o que pode estar ocorrendo; }\end{array}$ \\
\hline 7. Plausibilidade & $\begin{array}{l}\text { É guiado pela plausibilidade em vez de pela precisão, já que sensemaking refere-se mais à } \\
\text { reformulação de uma história para que ela se torne compreensiva do que pela verdade ou certeza. } \\
\text { Mesmo que agradável, a precisão não é necessária. }\end{array}$ \\
\hline
\end{tabular}

Figura 2. Sete propriedades da criação de sentido

Fonte: Adaptado de Montenegro e Bulgacov (2009), Vieira e Fonseca (2009) e Schroeder (2006).

Sintetizando o quadro 1 , pode-se dizer que o processo de construção de sentido organizacional é atuante em ambientes sensíveis, fundamentado na construção de identidades, na qual também participa o aspecto social, de abordagem retrospectiva, sempre em curso, focado na, e pela, extração de pistas. É social e dirigido pela plausibilidade. Sobre esta última característica, Czarniawska (2005) questiona: se a precisão é boa, por que ela não é necessária? O que seria necessário? Ela chega à seguinte resposta:

[ é necessário] algo que preserva plausibilidade e coerência, algo que é razoável e algo memorável, que encarna a experiência do passado e expectativas [...] algo que capta tanto sentimento quanto pensamento, algo que permite embelezamento para caber esquisitices atuais, algo que é divertido de contraste. Em suma, o que é necessário em construção de sentido é uma boa história (Weick, 1995, p. 60, tradução livre).

Com base em Weick (1995), Czarniawska (2005) defende que as histórias simplificam o mundo, sendo, portanto, úteis como guias para a ação, um dos objetivos da construção de sentido. Percebe-se assim uma relação direta entre discursos, que materializam as histórias, e ações. Van Dijk (1985) e Fairclough (2001, 2010) argumentam que discurso e ação são reflexivos sobre o mundo social, mas também fazem parte desse mundo. Portanto, o centro da construção de sentido são as palavras como uma espécie de trampolim para a ação: uma questão de linguagem, fala e comunicação (Weick, Sutcliffe, \& Obstfeld, 2005).

Para Van Dijk (1985), a primeira razão para se estudar a conversa é porque as pessoas fazem isso o tempo todo, cotidianamente, caracterizando a vida social. Assim, a realidade social é uma realidade construída subjetivamente na qual existem interpretações pessoais que podem ser compartilhadas a partir do desenvolvimento na conversa cotidiana de senso comum e regras para permitir que um entenda o outro. Para Fairclough $(2001,2010)$, essas regras são as chamadas ordens do discurso que são construídas em meio a lutas discursivas. De forma comparativa, pode-se relacionar a linguagem com a estrutura, as ordens discursivas com as práticas sociais - pois existe uma reiteração - e os textos com os eventos comunicativos, pois são mais pontuais. Nessa relação, é ressaltada pelo autor a possibilidade de resistência e de transformação da realidade, além da capacidade da análise de discurso crítica de desvendar relações de dominação por meio dos discursos e nos discursos (Fairclough, 2001).

Nesse sentido, Boje, Oswick e Ford (2004) salientam que é possível criar com a linguagem, sendo um visão limitada aquela em que a linguagem é percebida como simples ferramenta para descrever e relatar. E, quando o indivíduo cria, ele possui um ponto de vista cujo contexto permite conhecer a realidade e orientar suas próprias ações. Weick, Sutcliffe e Obstfeld (2005) postulam uma das características distintivas da construção de sentido: a problematização de um evento o leva à existência (o que é esta história aqui?) e traz significado para orientar ação (o que eu devo fazer?). Assim, "certos fenômenos são criados quando se fala sobre eles [e, portanto, os] membros da organização criam e constituem o ambiente a que reagem" (Malanovicz, 2011, p. 40). 


\section{Discurso como Prática Social}

Fairclough (2001) argumenta que a virada linguística nos anos 1970 reconheceu a linguagem como dimensão para se entender fenômenos sociais a partir dos discursos. E essa abordagem teórico-metodológica de análise do discurso vem sendo utilizada nos estudos organizacionais, já que permite "compreender como as práticas discursivas próprias do management e de outros contextos organizacionais são capazes de influenciar pessoas e estruturas, ou seja, como os discursos existentes nas organizações são construídos e quais suas implicações sociais" (Santos \& Bispo, 2013, p. 2).

Fairclough (2001) entende discurso como uma prática social capaz de tanto reproduzir quanto de transformar realidades sociais, sendo o sujeito da linguagem um sujeito-agente. Ele é moldado pelo ideológico e linguístico, mas tem possibilidade de ação transformadora de suas próprias práticas discursivas, contestando e reestruturando a dominação e as formações ideológicas socialmente empreendidas em seus discursos (Melo, 2009). Isso significa que o sujeito-agente pode se conformar às formações discursivas/sociais que o compõem, como também a elas resistir, ressignificando-as, reconfigurando-as (Melo, 2009).

O discurso como prática social é um dos pontos em comum dos autores que trabalham a análise de discurso crítica (Van Dijk 1997a, 1997b; Faiclough, 2001, 2012). Tais correntes de estudos, mesmo possuindo diferenças internas, tem uma uniformidade em seus pressupostos básicos, que são alinhar a crítica do social e da linguagem, dando foco ao contexto na produção discursiva (Guimarães, 2012) e perceber a existência do coletivo sendo produto e produtor, situação em que se constroi imagem de si e que legitima o que é dito (Pereira \& Brito, 2009). Compreender o discurso como prática social é reconhecer o discurso como modo de ação e inserir a questão das relações de poder nos estudos da linguagem.

Estudando Bakhtin e as relações de poder entre os discursos e sua dimensão política, Fiorin (2009, p. 153) afirma que "para o autor russo, não há uma neutralidade na circulação de vozes. Ao contrário, ela tem dimensão política. As vozes não circulam fora do exercício do poder". Carrieri, Saraiva, Pimentel e SouzaRicardo (2009) acrescentam que as marcas da ideologia que constitui os discursos podem ser explícitas ou implícitas e que a abertura para novas visões auxilia na compreensão do mundo do qual se faz parte.

\section{Produção de Sentidos sobre Participação Popular na Saúde}

Kreps (2009) aplicou o modelo de construção de sentido (Weick, 1995) para compreender complexidades inerentes ao sistema de saúde e guiar intervenções, destacando o papel central da comunicação. Neste trabalho, a temática da saúde também será abordada, mas de forma distinta da abordagem de Kreps (2009). Aqui, a saúde surge como pano de fundo da construção de sentidos sobre participação popular. Pye (2002) propõe que as palavras não possuem o sentido que o falante escolhe, pois o sensemaking depende do outro. Assim, o "sentido das palavras encontra-se na resposta gerada onde há um contexto e qualidade coletiva para as palavras e o fazer sentido delas" (Pye, 2002, p. 908).

Em processo de redemocratização do país, após 21 anos de ditadura militar e a efervescência de movimentos sociais na década de 1970, o Sistema Único de Saúde (SUS), conjunto de ações e serviços públicos de saúde, foi criado pela Constituição Federal de 1988. Vasquez et al. (2003) argumentam que a participação da sociedade na gestão das políticas públicas foi considerada como diretriz, quando da criação do SUS. Nessa nova concepção, a população estaria convocada a participar, de forma integrada, das deliberações do sistema público de saúde.

A Lei de $n^{\circ}$. 8.142 de 28 de dezembro de 1990 dispõe sobre a participação da comunidade na gestão do SUS. O artigo 10 trata da formação, em cada esfera de governo de instâncias colegiadas, sendo elas: as Conferências de Saúde e o Conselho de Saúde. As Conferências de Saúde são eventos com periodicidade de quatro anos, com a representação dos vários segmentos sociais. Seu objetivo é avaliar a situação de saúde e propor diretrizes para a formulação da política de saúde nos níveis regionais, municipais, estaduais e nacionais.

Klein Jr., Salm, Heidemann e Menegasso (2012) afirmam que a administração pública tem o papel de mediar e promover um espaço público propício à deliberação coletiva, para que os cidadãos possam fortalecer seu senso de justiça e participação. Citam como exemplos de mecanismos de participação as assembleias de cidadãos, os júris de cidadãos, os grupos focais, plebiscitos, orçamentos participativos, referendos, surveys, paineis de pesquisa, bate-papos interativos e páginas de internet.

Vasquez et al. (2003) também defendem a ideia de um processo de participação. Os autores utilizam o modelo de classificação de Arstein e explicam que a participação nas políticas públicas ocorre nos níveis simbólico e demcontrole cidadão. O primeiro nível é considerado mais básico, e se refere apenas à utilização dos serviços, e não há partilha de poder. Já no segundo nível, o poder é compartilhado e se estende até o poder delegado. Torna-se mais complexo de acordo com o grau de envolvimento no processo. Além disso, os autores também identificam que, do ponto de vista das organizações, as possibilidades de participação podem ser diferenciadas em meio ou fim. A primeira diz respeito à utilização da participação para determinado objetivo institucional. Já a segunda, reconhece a sua importância nas decisões, promovendo espaço democrático para controle social das instituições (Vasquez et al., 2003).

Na visão de Bahia, Costa e Stralen (2007), há uma preocupação dos Conselhos de Saúde em seguir estratégias de ação que priorizem e convoquem maior participação popular nas deliberações públicas da saúde. 
Uma lista de prioridades resultantes da reunião do Conselho Nacional de Secretários Estaduais de Saúde de 2007 era composta de ações propostas como a realização de Conferências Municipais, Estaduais e Nacional de Saúde, a implementação das ouvidorias e a instituição de critérios de rotatividade dos conselheiros (Bahia, Costa, \& Stralen, 2007).

Contudo, apesar de toda a legitimação discursiva descrita em defesa da participação popular, caracterizase como uma mudança radical a apropriação da população para formulação de políticas públicas, sendo um processo complexo ligado ao grau de consciência política, organização e mobilização social (Brasil, 2007). Camargo-Borges e Mishima (2009) justificam essa complexidade pela questão histórica em torno do eixo que traz um movimento paradoxal na participação. Enquanto as novas políticas valorizam a participação, a história do Brasil nos remete a um contexto oposto, o que dificulta a implementação da participação como deliberação coletiva. Acrescenta outro fator problemático na questão:

Como a participação não é algo que se nomeia e institui por decreto, o controle social pode ser uma ferramenta legítima de democratização da saúde, como também pode se transformar em uma forma de cooptação do poder estatal, como uma instância para aprovação de projetos na saúde, numa forma de participação passiva da sociedade (Camargo-Borges \& Mishima, 2009, p. 32).

Portanto, Vizeu e Bin (2008) apontam para a necessidade de se ter um olhar crítico para a questão dos conselhos, a fim de se evitar uma "falsa sensação de democratização". Ele argumenta que nem sempre os conselhos são espaços de construção coletiva e com igualdade político-participativa entre seus membros, já que muitas vezes eles são usados pelo governo para apresentar propostas prontas a seus membros. Oliveira (2004) esclarece ainda alguns pontos sobre a relação entre sociedade civil, governo e os conselhos:

[...] muitos governos, autoridades públicas e gestores da saúde avaliam que a maioria dos conselheiros, principalmente os representantes dos usuários, é técnica e socialmente despreparada para perceber com clareza a lógica de funcionamento e as necessidades do sistema de saúde. Já outros argumentam que os conselhos são instâncias inócuas para melhorar politicamente o funcionamento do sistema de saúde porque costumam ser transformados em instâncias de conflitos, de impasses político-partidários, ou servindo como trampolim político para muitos de seus membros, deixando em plano secundário as reais necessidades de discussão e decisão sobre as questões de saúde (Oliveira, 2004, p. 64).

Para Vizeu e Bin (2008, p. 90), a participação popular deveria ser uma democracia deliberativa, isto é, um "entendimento sobre o processo democrático centrado na prática discursiva, onde a argumentação racional e os procedimentos equitativos para a participação discursiva e decisória são os critérios de igualdade democrática". Os autores ainda apontam como possível solução para a operacionalização da democracia na modernidade a utilização da ação comunicativa em substituição à ação estratégia. A diferença entre as duas baseia-se nas relações entre sujeitos. Enquanto a ação estratégia considera um dos sujeitos como objeto a ser manipulado para a obtenção de um fim, caracterizando uma ação racional-instrumental monológica, a ação comunicativa pressupõe um acordo compreensivo entre os atores para que possam coordenar juntos seus planos de ação.

Diante do exposto, é possível perceber a evidência de alguns sentidos construídos sobre participação popular no Brasil: participação como prescrição da legislação, participação como deliberação democrática, participação como utilização de serviços, participação como compartilhamento de poder delegado, participação como objetivo institucional e participação como promoção política pessoal. Portanto, faz-se necessário analisar a complexidade na qual a organização está inserida, com o intuito de compreender quais e como os sentidos foram construídos no contexto particular de um centro de saúde, objeto de estudo desta pesquisa.

\section{Metodologia}

Neste trabalho, inicialmente, os pesquisadores visavam avaliar a comunicação sob um paradigma não tradicional, no qual se considera que não existe um processo linear de emissão-recepção de mensagens, mas de uma interação contínua e que ocorre na vida cotidiana da organização e fora dela. A intenção era, a partir dessa percepção não ferramental, propor estratégias de comunicação alinhadas à participação popular que levassem em conta o contexto comunicativo vivenciado por vários atores sociais e não somente pela alta gestão pública. Contudo, durante a pesquisa, foi percebido que os atores estudados não compartilhavam o mesmo sentido de participação popular. Isso instigou os pesquisadores a tratar dessa nova questão: quais são os sentidos construídos da temática participação popular na saúde pública por diferentes atores sociais relacionados a um Centro de Saúde de Belo Horizonte?

Neste artigo, valeu-se de uma pesquisa descritiva, qualitativa, para a compreensão do fenômeno da construção de sentido de conceitos sobre a participação popular. Foi utilizado o estudo de caso pela crença na possibilidade de melhor compreensão de aspectos singulares de um caso. Stake (1994) defende que o estudo de um caso pode ser empregado como forma de compreensão específica de situações sociais, as quais possuirão um funcionamento específico e se constituirão em um sistema integrado. Assim, mesmo não sendo sempre fácil, é possível identificar características significantes que estariam dentro ou fora do sistema, permitindo delimitações. Contudo, não se pode deixar de reconhecer elementos contextuais influenciadores nesses sistemas. 
Além disso, na perspectiva de Stake (1994), o estudo de caso pode ser considerado tanto como processo de conhecimento sobre um caso quanto produto de conhecimento, posição que coaduna com a perspectiva neste artigo, que visa ampliar o debate sobre posições amplamente aceitas sobre o discurso - que é visto comumente como representação da realidade - e a construção de sentido, mais especificamente, da participação popular nas políticas públicas.

O objeto empírico foi o Centro de Saúde São Paulo (CSSP), localizado na cidade de Belo Horizonte. Foram analisados dois grupos de atores que interagem com a organização: gestores e membros da Comissão Local de Saúde. Quanto à caracterização dos entrevistados, salienta-se que mesmo os sujeitos sendo considerados no mesmo grupo, apresentam diferenças contextuais significativas. Foram selecionados funcionários de diferentes cargos de gestão, como gerentes e administradores; e de diferentes níveis hierárquicos e natureza de atividade, como unidade básica que lida com atendimento primário de saúde, gerência distrital que administra as unidades de saúde, e secretarias administrativas tanto municipais quanto estaduais. Essa diferenciação traz amplitude em relação aos dados, mas é necessário ressaltar que eles vivenciam contextos diferentes.

Já a Comissão Local de Saúde, é composta por membros da comunidade e servidores do centro de saúde. Seus 14 membros, representantes da comunidade, estão na faixa etária entre 62 a 78 anos e, destes, seis participaram da pesquisa. Vale ressaltar que dois participantes foram fundadores da Comissão, somando 42 anos de participação. Outro membro atua há 10 anos e os outros três ingressaram no grupo entre dois e três anos. O grupo reúne-se mensalmente para discutir sobre as demandas locais relacionadas ao CSSP.

Os instrumentos de coleta utilizados foram entrevistas semiestruturadas com cinco gestores públicos (gerente do Centro de Saúde São Paulo, gerente do Distrito Sanitário, secretário da Regional Nordeste, Coordenador Geral do projeto Mobiliza SUS da Secretaria Municipal de Saúde e administrador público da Secretaria de Estado de Saúde) e grupo focal com os membros da Comissão. Segundo Costa (2008), o grupo focal busca compreender aspectos que são tendências em determinado grupo, normalmente valores, princípios e motivações que regem a percepção das pessoas por meio de uma entrevista coletiva. Além disso, foram coletados dados secundários em sites governamentais e consulta a documentos oficiais.

Os dados foram analisados à luz do referencial teórico-metodológico da análise crítica do discurso. Fairclough (2001) fornece um quadro da teoria social do discurso, também conhecida como tridimensional por permitir a análise do discurso como texto, como prática discursiva e como prática social.

A primeira dimensão, texto, se configura como a unidade mínima de análise dos discursos e ultrapassa o sentido como puramente produções escritas. Além da linguagem verbal, oral e escrita, são incluídos no sentido os textos imagéticos. Fairclough (2001) considera que os signos são socialmente motivados, não havendo uma base racional para combinar um significante particular com um significado particular. Um exemplo seria a distinção entre "terrorista" e "lutador pela liberdade" que configuram vocabulários diferentes para sentidos distintos. Além disso, há uma diferença entre significado potencial de um texto e sua interpretação, conferindo ao intérprete a possibilidade de redução de ambivalência existente nos textos quando escolhe um sentido particular ou pequeno conjunto de sentidos alternativos. A categoria selecionada para análise do corpus desta pesquisa foi vocabulário, que inclui tanto a análise lexical buscando a significação das palavras quanto a análise de metáforas (Fairclough, 2001).

A segunda dimensão, prática discursiva, focaliza os processos de produção, distribuição e consumo textual (Fairclough, 2001). Percebe-se que existe uma estreita relação entre a construção de sentido e a análise das práticas discursivas por darem atenção tanto ao processo de produção quanto de recepção dos textos. As categorias selecionadas para a análise foram força dos enunciados e intertextualidade (produção), cadeia intertextual (distribuição) e coerência (consumo).

A terceira dimensão é a prática social. O objetivo desta análise é especificar "a natureza da prática social da qual a prática discursiva é uma parte, constituindo a base para explicar por que a prática discursiva é como é; e os efeitos da prática discursiva sobre a prática social" (Fairclough, 2001, p. 289). É a partir da prática social que são percebidas as relações da linguagem com ideologias e hegemonias. As categorias selecionadas para a análise foram ordens de discurso e efeitos políticos e ideológicos do discurso.

Com base nas três dimensões do discurso, chegou-se a seis categorias de discurso, distintas possibilidades de conceber a participação: a) como prescrição da legislação; b) como objetivo institucional; c) como compartilhamento de poder delegado; d) como utilização de serviços; e) como promoção política pessoal e f) e como fator econômico para legitimação da qualidade do SUS. Vale salientar que as categorias são divididas a título de análise, não havendo uma ordem e nem um modelo pré-definido. Portanto, as escolhas foram feitas de acordo com as peculiaridades da pesquisa e cada parte do corpus de análise.

\section{Apresentação e Análise dos Resultados}

Como neste artigo busca-se compreender quais e como são os sentidos construídos da temática participação popular na saúde pública por diferentes atores sociais relacionados a um centro de saúde de Belo Horizonte, a ênfase das análises recaiu sobre os aspectos de identificação e aos efeitos do discurso. Os resultados foram organizados, assim, apresentando incialmente a ordem de discurso hegemônica que configura 
práticas sociais e, posteriormente, foram apresentadas as possíveis construções de sentido que orientam o discurso, não deixando de considerá-lo como prática social.

\subsection{Participação como Prescrição da Legislação}

A primeira categoria se relaciona à construção de sentido da participação como prescrição da legislação. Na percepção dos gestores, não somente a Comissão Local do CSSP, como instância de representação, mas a própria comunidade do entorno é participativa.

A comissão local do bairro São Paulo é bem participativa. Aliás, a comunidade é participativa. Lá tem muitos líderes comunitários, o que não acontece em todos os centros de saúde. Quanto mais participativo, mais ações o centro de saúde consegue desenvolver e isso depende muito também do perfil do gestor/trabalhador. (Gerente do Distrito Sanitário Nordeste)

Analisando a dimensão texto, a partir da proposta de Fairclough (2001), utiliza-se a categoria vocabulário que está relacionada com a escolha lexical da construção textual. Ao utilizar a expressão "bem participativa", percebe-se a ideia de que ser mais participativo é bom. O gestor é destacado como um ator importante no que diz respeito à participação, sendo seu trabalho legitimado, o que configura uma posição ideológica e permitindo a identificação da identidade social do ator.

A caracterização do centro de saúde como "mais participativo" refere-se também à existência de muitos líderes comunitários e à presença dos representantes nas reuniões do Conselho de Saúde. Sobre a atuação nos conselhos, a gestora discorre:

As diretrizes do SUS exigem que haja controle popular para se adequar à política e logo receber o repasse de verba. Dessa forma, os projetos de maior relevância da Secretaria Municipal de Saúde precisam passar pela aprovação do Conselho Municipal de Saúde, inclusive aprovação orçamentária. (Gerente do Distrito Sanitário Nordeste)

Observa-se que a gestora considera a participação popular como a aprovação de projetos pelo Conselho Municipal de Saúde. Além disso, defende que as diretrizes do SUS estão sendo atendidas uma vez que o repasse de verba só acontece se o projeto se adequar à política, passando pela aprovação do Conselho. No que se refere à estrutura, o discurso assume uma argumentação mais objetiva quando explicita que "as diretrizes do SUS exigem". Em outras palavras, excluindo-se os decisores, parte-se de uma visão formal, endossada por documentos oficiais e pela linguagem mais objetiva dos gestores, configurando a participação como prescrição da legislação. Neste trecho, é interessante notar que o gestor enfatiza a expressão “inclusive aprovação orçamentária" como forma de justificar a relevância da participação, deixando explícito que o aspecto econômico é central no seu pensamento sobre o tema.

Como elementos da prática discursiva, tem-se a produção, a distribuição e o consumo de textos. Quanto à produção, pode-se analisar a intertextualidade. Há um forte diálogo entre os trechos discursivos acima e a Constituição Federal de 1988. O discurso explicita que a legislação determina o controle popular; que o controle popular é necessário para repasse de verbas; que os projetos de maior relevância precisam passar pela aprovação do Conselho Municipal de Saúde; que o controle popular é efetuado pelo Conselho Municipal de Saúde, e que o controle social representado pelo sistema de conselhos. Tanto a participação quanto as diretrizes do SUS, bem como a questão de aprovação orçamentária são ideias expressas na carta magna brasileira. Assim, observa-se que a legislação dialoga com os discursos dos gestores, conferindo um pano de fundo para pressuposições.

A respeito do consumo, é possível analisar a coerência dos textos. Percebe-se a defesa da ideia de que a presença de representantes nas reuniões do conselho configura o sentido da participação, a qual ocorre a partir da aprovação de projetos pelo conselho. Este tem importância por legitimar decisões tomadas pelos gestores. Contudo, analisando a heterogeneidade e a ambivalência dos textos, percebe-se que há uma marginalização do sentido de participação que estimula o debate e que seja mais qualitativo do que quantitativo. Nesse sentido, como análise da prática social, é possível problematizar que a valorização da participação é regida pela lógica econômica, na qual se tem valor por viabilizar destinação de verbas e não pelo estímulo ao debate, tendo o conselho importância por legitimar as decisões tomadas pelos gestores. Como efeitos políticos e ideológicos do discurso, tem-se a reprodução da estrutura social baseada no neoliberalismo.

\subsection{Participação como Objetivo Institucional}

A segunda categoria de discurso diz respeito à construção de sentido da participação como objetivo institucional. Em tal ideia, fica explícita a relação direta entre participação e atuação dos gestores/ centro de saúde.

Teve um centro de saúde na Nordeste que fez um evento para os idosos e mobilizou a comunidade para ajudar no evento. Eles chamaram 600 idosos e compareceram 500. Havia 100 profissionais em mutirão fazendo atendimento. Com recursos da comunidade, eles conseguiram pratos com o Buffet, almoço para todos em restaurantes, entre outras 
coisas. Mas foi uma iniciativa da unidade em parceria com a comunidade. [ ...] Outro caso, foi no combate à criança desnutrida. Teve centro de saúde que conseguiu parceria com sacolão que cedeu os legumes, frutas e verduras para o centro de saúde fazer demonstrações com as mães dessas crianças. (Gerente do Distrito Sanitário Nordeste)

Os gestores se utilizam da recursividade para construir sentido (Schroeder, 2006; Montenegro \& Bulgacov, 2009). A vivência da gerente do distrito, por estar mais próxima a diferentes centros de saúde, permite a ela construir um sentido de participação mais ligado à cooperação do que à reclamação e à cobrança. As escolhas lexicais "parceria" e "mutirão" na construção dos discursos do trecho anterior exemplifica isso. Na percepção dos gestores, a participação varia de acordo com a comunidade. Contudo, o gestor da organização possui papel influente na participação e mobilização, reforçando o sentido de objetivo institucional.

A participação varia muito. Pela minha experiência, percebo que quanto mais carente é uma comunidade, há mais participação. (Gerente do Distrito Sanitário Nordeste)

Então quando você tem uma comunidade que não atua muito, mas a gerência e os funcionários são pró-ativos, você puxa e você consegue resultados positivos. (Secretário da Regional Nordeste)

Quanto à produção discursiva, percebe-se que a força do enunciado "você puxa e você consegue resultados positivos" a assemelha a uma promessa, de resultados positivos não dependentes da comunidade. É possível, assim, conseguir participação mesmo que a comunidade não seja atuante, desde que haja ação, desde que haja funcionários proativos. O discurso do gestor se configura no sentido de estimular a ação, colocando o centro de saúde como elemento central no processo.

Analisando as práticas sociais, pode-se associar a característica do discurso do gestor (Secretário Municipal) às concepções de organização empresarial, negligenciando aspectos da organização pública, que depende de demandas sociais. Dessa forma, é possível perceber que fica explícita a consideração do centro de saúde como protagonista das ações, dependendo dele a iniciativa de mobilização.

O sentido do objetivo institucional não está relacionado apenas aos centros de saúde, mas também às comissões como instituições de função pública. Os membros da comissão ressaltaram que a participação da comunidade está diretamente relacionada ao sucesso das atividades da comissão, como nos casos de bairros vizinhos que conseguem realizar grandes obras, modificações e melhorias por meio de uma maior participação popular. Entretanto, os participantes afirmaram que as comissões não se comunicam entre si. A diferença entre o que uma comissão consegue ou não realizar na comunidade pode refletir o grau de mobilização da comunidade e da atuação da comissão. Assim, questiona-se a legitimidade da comissão perante a população local. Se ela não consegue mobilizar a comunidade, como representa seus interesses? Está compartilhando os mesmos sentidos com a comunidade que representa?

Bairros novos fazem coisas que não conseguimos [...] Os outros bairros não mostram não! É muito egoísmo. (Comissão Local de Saúde)

No trecho anterior, os bairros são personificados para dar mais concretude à narrativa, adjetivando as ações: “É muito egoísmo". O grupo focal apontou a disputa por obras no orçamento participativo como justificativa para esse "egoísmo", que por sua vez é fruto da própria lógica do orçamento participativo, já que uma mesma região pode não ser totalmente beneficiada pela obra indicada à votação pelo poder público. É nesse sentido que alguns autores questionam se a participação ocorre de forma deliberativa, pois pode envolver apenas o resultado e não o processo de construção coletiva (Vizeu \& Bin, 2008; Rosemberg, 2009). Ainda sobre o orçamento participativo, pode-se analisar o discurso do gestor:

Um exemplo que nós podemos citar aqui na Nordeste. Nós temos na nossa rede aqui 20, 21 centros de saúde, sendo que 10 deles foram, através do orçamento participativo, construídos novos. Isso representa quase $50 \%$ dos centros de saúde. E que foi definido pela própria população. Aliamos aí os recursos que são repassados pelo município com as prioridades que a população acha importante. (Secretário da Regional Nordeste)

Como análise da prática social, percebe-se novamente a questão financeira como pano de fundo da questão da participação, mas dessa vez relacionada aos resultados do orçamento participativo, que justifica e viabiliza ações.

\subsection{Participação como Compartilhamento de Poder Delegado}

A terceira categoria se relaciona à construção de sentido da participação como compartilhamento do poder delegado. Ao contrário dos gestores, a Comissão Local do CSSP afirma que a comunidade tem pouca ou nenhuma participação. Os membros consideram como participação a procura da comissão pela comunidade, seja para se tornar membro, participar de reuniões, ou se oferecer para alguma ação que beneficie o serviço prestado no Centro de Saúde. 
Para chamar para assembleia, é só no boca a boca [ ...] O povo não vem! Nem adianta fazer nada! O pessoal não interessa por nada [ ...] passamos as informações quando dá. Tem muitos que já sabem. (Comissão Local de Saúde)

Considerando a análise textual, tem-se o uso de "o povo" e "o pessoal", respectivamente, como sujeitos das frases negativas "não vem" e "não interessa por nada". Pressupõe-se, assim, que os representantes da comissão desejam o contrário. O lado positivo seria então "o povo" ou "o pessoal" participar, procurar a comissão. Além disso, é possível perceber um elemento identificatório do ator social que discursa, que distancia a voz que fala da voz que deveria participar: os participantes da comissão não utilizam "nós", como, por exemplo, "nossa comunidade não se interessa".

Durante o grupo focal, foi possível observar algumas fissuras na construção de sentido da participação, como no caso das reclamações dos usuários, que não são consideradas como participação pelos membros da comissão. Para eles, os efeitos dessa situação de não interesse e não participação são diversos, tais como não haver nenhum tipo de remuneração, falta de vontade, descrédito, entre outros.

Ainda sobre o processo de construção de sentido, ele busca mais plausibilidade do que precisão (Schroeder, 2006; Montenegro \& Bulgacov, 2009). No trecho a seguir, é interessante observar que a voz do entrevistado diminui no momento em que ele caracteriza a forma como o conselho funciona. Isso pode ser um demonstrativo de dúvida, de incerteza, uma vez que ele fala de forma generalizada sobre a atuação do Conselho, sem considerar particularidades das microrregiões. Na última frase, o gestor cita posições de controle duas vezes, "podam" e "fazem cobranças em outros", e, quando se refere à parceria, inclui o léxico "em alguns casos", demonstrando que não é algo comum, rotineiro, ser parceiro. Fica implícito que é mais cotidiana a reclamação.

A saúde é muito mais avançada que qualquer outra área. O que a gente chama de controle social, a saúde é muito bem estruturada. Ela criou o sistema dos conselhos regionais, nós temos nosso conselho que funciona, de forma [ voz diminui] sistemática, que atuam de forma muito [ voz diminui] eficiente. Podam, são parceiros em alguns casos e fazem cobranças em outros. (Secretário da Regional Nordeste)

Mesmo assim, os gestores consideram que as Comissões Locais de Saúde possuem um papel muito importante na participação popular. Vasquez et al. (2003) afirmam que a criação de Conselhos, Conferências e outros espaços institucionalizados ampliaram a possibilidade de participação da população. De acordo com o modelo de classificação de Arstein, que classifica a participação em políticas públicas em dois níveis, simbólico e controle cidadão, infere-se que a participação a qual se refere à gestora está no segundo nível. Essa classificação se deve ao fato de haver certo poder compartilhado e delegado, na medida em que existem pessoas delegadas a participarem do Conselho e por haver necessidade de aprovação, ou seja, existe uma instância de decisão nessa relação. Portanto, o trecho acima demonstra uma construção de sentido de participação como compartilhamento de poder delegado, o que pode causar certo incômodo nos gestores pelas constantes cobranças e pressões por melhores serviços. Ainda nesse contexto, é interessante observar que o gestor aponta para um fato constante em Belo Horizonte referente aos representantes das comunidades nos conselhos.

Eu acho que o conselho tem tido um papel muito importante na saúde. Claro que, assim como nos outros conselhos, as coisas são meio que... As mesmas pessoas. E eu acho que isso não é bom. Umas das coisas que a gente tem buscado e o prefeito já atentou a isso. [ ...] Os comerciantes tem que estar lá dentro. O empresário. Não é só aquele grupo que às vezes você vai na comissão local e são sempre os mesmos. (Secretário da Regional Nordeste)

O gestor explica que, geralmente, as mesmas pessoas participam sempre de vários conselhos dentro de uma comunidade. Analisando a distribuição de textos na dimensão da prática discursiva, no trecho “as coisas são meio que... As mesmas pessoas. E eu acho que isso não é bom", percebe-se que ele tenta buscar palavras para minimizar um aspecto que ele considerava negativo na sua fala. Ele acredita que deve ser diferente a participação nos conselhos, com a inclusão de outros representantes da sociedade, e endossa a sua posição citando o "prefeito", que atua como personagem de autoridade na construção do discurso.

Dessa forma, observa-se que a cadeia textual na qual o discurso se insere depende, por exemplo, do discurso de gestão defendido pelo prefeito municipal. Para contextualizar, ex-empresário, o prefeito citado manteve em seu mandato os principais postos da administração central e de empresas públicas nas mãos de ex-funcionários da Construtel e Batik, empresas que pertenceram a ele. Esse é um dos fatos que ilustram o tom empresarial de sua gestão municipal. Assim, o discurso atua como prática social defendendo interesses específicos (Boje, Oswick, \& Ford, 2004). Além disso, percebe-se que há conteúdos implícitos no discurso acima. Percebe-se uma defesa do empresariado no Conselho como forma de legitimar a gestão pública com contornos privados. Contudo, problematiza-se: qual o sentido de comerciantes e empresários estarem lá dentro? Estariam representando os interesses de quem? Não seriam eles usuários dos planos privados de saúde, assim como o é o próprio gestor? Nesse sentido, as fronteiras entre público e privado são dissolvidas. Além disso, quando o gestor defende a renovação nos conselhos, é interessante observar que, em nenhum momento, foram pontuados possíveis motivos ou interesses pessoais que fazem com que os membros da comissão permaneçam no grupo. Levando-se em consideração que alguns possuem mais de 40 anos como membros da comissão, esse fato e seus aspectos simbólicos precisam ser analisados para uma análise adequada da situação. 


\subsection{Participação como Utilização de Serviços}

A quarta categoria foi a construção de sentidos da participação como utilização de serviços. De acordo com os gestores, o contexto histórico de cada comunidade interfere no nível de participação popular. O CSSP surgiu em um contexto onde sua implantação foi demandada pela comunidade local e, portanto, os gestores entendem que a participação deveria ocorrer, por ter partido da própria população. Para compreender o contexto histórico que envolve a comunidade do CSSP, a gestora contou um pouco sobre a história desde o surgimento da unidade, utilizando a memória novamente como recurso para a construção de sentido.

Sobre o bairro São Paulo, é importante lembrar que foi um bairro surgido com o Curtume Santa Helena. [ ...] A partir da necessidade dessas pessoas, começaram a surgir os primeiros pontos do bairro como a Igreja, o centro de saúde, o CAC. Então, podemos dizer que veio de demanda da comunidade. [...] A partir disso, a gente vê hoje como a comunidade é mais participativa, inclusive a comissão local é muito atuante. (Gerente do Distrito Sanitário Nordeste)

Nesse discurso, fica explícita a percepção da gestora quanto à possibilidade de influência do contexto histórico na questão da participação popular de uma comunidade. Peruzzo (2007) aponta que, após o fim da ditadura militar, movimentos e associações populares tomaram conta do cenário social do Brasil, principalmente em bairros periféricos, como formas de mobilização e conscientização de uma população com várias carências e insatisfações quanto à moradia, saúde, transporte, dentre outros. A partir da escolha lexical "veio de demanda da comunidade", a gestora legitima a participação como demanda por serviços a partir da necessidade, configurando um aspecto assistencialista da díade participação-gestão.

Contudo, analisando a cadeia intertextual na dimensão da distribuição de textos, percebe-se que esse sentido não é compartilhado entre todos os gestores, o que denota a alta ambiguidade presente na questão. Os gestores mais distantes da realidade cotidiana do centro de saúde e mais ligados diretamente à alta administração municipal, por exemplo, defenderam a participação como presença de representantes da comunidade nos Conselhos e ainda com a participação de empresários. Tais construções de sentidos diferentes permite a seguinte problematização: qual o sentido de "comunidade" para os diferentes gestores?

A partir dessas pistas, o sentido de participação construído parece legitimar posições de cada gestor, partindo de seus compromissos com o governo, de seus contatos sociais e de suas identidades, que mesmo em processos mentais internos, o indivíduo leva em consideração a situação em que se encontra, seu contexto, sendo atividade contingencial aos seus pares. Isto é, o discurso se configura como prática social.

\subsection{Participação como Promoção Política Pessoal}

Durante a realização do grupo focal, o fator simbólico foi o que mais chamou a atenção dos pesquisadores. A participação como promoção política pessoal foi a tônica percebida como sentido compartilhado entre os membros do grupo. Os participantes relataram seus sentimentos por pertencerem à comissão. Em diversos momentos se apresentaram como exemplos para a comunidade pela realização de um trabalho em razão do interesse público. A análise lexical confirma tais ideias: "privilégio" e "honra". E este é um elemento contextual que deve ser observado, pois esse sentido não é compartilhado com os gestores que defendem a renovação dos membros. Alguns participantes dedicaram mais de 40 anos de suas vidas junto à comissão. Portanto, criar políticas que os impeçam (ou dificultem) de participar em virtude de novos membros pode gerar uma mobilização de resistência e desvalorizar cidadãos que dedicaram grande parte de suas vidas à participação na política pública.

Nossa função é trazer direitos, deveres e oportunidades certas para os usuários. Não posso trazer informações duvidosas [ ...] É um privilégio, uma honra participar. (Comissão Local de Saúde)

Nós estamos calejados. Infelizmente, se eles soubessem a força que a comunidade tem... Mas o povo tem uma preguiça tão grande! O povo prioriza a novela [ ...] O povo só quer saber se tem salário. Quanto que vai ganhar [ ...] O povo fala: o que adianta eu ir lá se não vai resolver nada? (Comissão Local de Saúde)

Discursivamente, percebe-se que os representantes da comunidade na comissão não se consideram como "povo", um recurso que empregam para criticar a falta de interesse desse "povo". Eles se referem a "nós" quando falam da comissão e a "eles" quando falam da comunidade em geral. Isso pode refletir a ideia de uma comunidade não participativa, não mobilizada, e também de afastamento dos representantes daqueles de que deveriam estar próximos. Isto é, não atuam com um objetivo em comum. Dessa forma, cria-se certo distanciamento entre "nós" e "eles", como se os representantes da Comissão falassem em nome do poder público e não da comunidade a qual pertencem. Além disso, quando os integrantes se separam do "povo", eles reafirmam seu papel de representante, que tem uma função pública e, dessa forma, certo status de nobreza.

As escolhas lexicais "se tem salário" e "quanto vai ganhar" pressupõem uma mercantilização da participação que deveria resultar numa troca. Analisando o consumo dos textos na dimensão da prática discursiva, a coerência do texto seria proporcionada sugerindo que a troca esperada seja a solução de algo, isto é, se houvesse uma expectativa de solução de problemas, as pessoas participariam. Contudo, o texto possui uma heterogeneidade quanto ao que seria o resultado dessa troca. Além do aspecto sugerido para dar coerência ao texto, o discurso permite inferir também que se houvesse troca por dinheiro ou outro ganho 
contável, haveria mais participação. Mas afirmar isso pode prejudicar o sentido de nobreza e honra que permeou o discurso dos membros da comissão.

Independente das possibilidades de sentido para as trocas, percebe-se uma lógica de mercado como reguladora das relações sociais e políticas. Tal prática social reproduz a ideia de avanço da interferência do capitalismo inclusive na vida social e nas políticas públicas.

Por fim, é interessante observar que os membros da Comissão Local do CSSP e os gestores compartilham um mesmo sentido, mesmo partindo de processos de construção diferenciados:

A comunidade não sabe do poder que ela tem. Uma comunidade organizada coloca um município para frente. (Gerente do Distrito Sanitário Nordeste)

O povo só sabe reclamar! Poderíamos ter coisas melhores! Eles não sabem a força que uma associação de bairro tem junto ao poder público. Quem luta, alcança. (Comissão Local de Saúde)

\subsection{Participação como Fator Econômico para a Legitimação da Qualidade do SUS}

A ordem de discurso identificada que permeou todas as construções de sentido nos discursos foi o fator econômico como legitimação da qualidade do SUS. Como efeitos, percebe-se que ela atua de forma a reproduzir uma estrutura social vigente, conforme será detalhado a seguir.

Partindo de um pressuposto que culturalmente o SUS é visto como serviço de qualidade ruim pela população brasileira, o gestor traz uma questão técnica, de forma objetiva, para argumentar que é investido dinheiro na saúde e que o serviço não pode ser considerado ruim pelo fato de ser gratuito.

A gente tem que começar a repensar essa coisa de sistema público. Porque os procedimentos mais caros são tudo pago pelo SUS. Não é pago pelos planos de saúde. Os medicamentos para tratamentos mais caros são bancados via programa de governo. [ ...] Isso [ melhorar infraestrutura física] é forma de valorizar o atendimento e não dizer que o serviço público pode ter qualquer coisa porque é gratuito. Não é. (Secretário da Regional Nordeste)

Analisando os aspectos lexicais, o gestor utiliza o sujeito "a gente" buscando responsabilizar todos, o incluindo, pelo pensamento negativo sobre o sistema público. A expressão "coisa de sistema público" reflete uma noção de algo problemático, indefinível. Em relação à coesão, a conjunção "porque" exemplifica o aspecto de justificação do discurso sobre o SUS. O sujeito do discurso se preocupa em explicitar justificativas para suas falas, tendo em vista que o discurso pode ser ambivalente para um intérprete particular. Um exemplo é a avaliação da qualidade do SUS (ruim x boa).

A respeito da prática discursiva, analisando a coerência, percebe-se a existência de uma contradição entre discurso e ação quando se liga o trecho acima com o seguinte:

Me preocupa muito. Uma das justificativas é que demora. Ora, eu me cito como exemplo. Tem consulta da minha mulher que demora 6 meses. Marcada no [ Plano de Saúde]. E paga convênio. No entanto, demora do mesmo jeito. (Secretário da Regional Nordeste)

O gestor utiliza um raciocínio comparativo com os planos de saúde privados para exemplificar seu argumento que se constroi de forma contraditória. Com o posicionamento de gestor, o entrevistado se identifica com a qualidade do SUS. Contudo, como usuário de serviços de saúde, ele se coloca como exemplo para dizer que a situação da saúde é semelhante tanto nos equipamentos públicos quanto privados e, portanto, a demora em marcação de consultas não deveria ser alvo de tantas críticas. Fica explícita a contradição quando o entrevistado diz acreditar na qualidade do SUS como discurso, mas como ação ele privilegia planos privados. Percebe-se, assim, que os ambientes não são monolíticos, havendo diferenças de posicionamentos que condicionam as ações e os discursos e que tem relação estreita com a construção de identidade (Schroeder, 2006; Montenegro \& Bulgacov, 2009).

Também se pode analisar a prática discursiva por meio da intertextualidade. Algumas pressuposições dos discursos acima estão ligadas a outros textos, como a necessidade de repensar concepção sobre sistema público (baseia-se na percepção geral da população sobre o SUS) e os procedimentos mais caros serem pagos pelo SUS (baseia-se na Constituição Federal).

Analisando a prática social, observa-se que o fator econômico é utilizado para legitimação de discursos: se é investido muito dinheiro, o serviço não pode ter má qualidade. Nesse sentido, os aspectos simbólicos são marginalizados e os outros fatores que podem levar a uma qualidade inferior são silenciados. Um serviço de saúde não é apenas construção de equipamentos, distribuição de remédios e contratação de médicos. As pessoas que estão envolvidas no atendimento, desde a recepcionista do centro de saúde até o cirurgião do hospital são responsáveis pela prestação do serviço como um todo. E, como pessoas que são, precisam ser analisadas a partir de seu contexto simbólico e cultural. 


\section{Considerações Finais}

O objetivo neste artigo é identificar quais e como os sentidos sobre a participação popular são construídos por diferentes atores sociais relacionados a um centro de saúde de Belo Horizonte. Diante do exposto, pode-se perceber diferentes construções de sentido (Weick, Sutcliffe, \& Obstfeld, 2005) sobre o conceito participação popular, como prescrição da legislação, deliberação democrática, utilização de serviços, compartilhamento de poder delegado, objetivo institucional e promoção política pessoal. Esses sentidos não são aleatórios, pois discurso expressa a compreensão de eventos sociais (Van Dijk, 1985) e orienta a ação (Weick, Sutcliffe, \& Obstfeld, 2005). Esses processos não são estáticos nem isentos de ambiguidades. Dependem do posicionamento do indivíduo, do ambiente, da recursividade, da não linearidade entre fala e ação (Schroeder, 2006; Montenegro \& Bulgacov, 2009).

Além disso, observa-se que os discursos são práticas sociais (Boje, Oswick, \& Ford, 2004). Eles levam um evento à existência e a sua construção está baseada em um posicionamento político, que defende ideias e interesses próprios em detrimento de outrem. Os gestores, por exemplo, buscam legitimar a sua função, o governo, a qualidade do SUS, o seu papel como relevante na participação popular e a renovação nos membros da Comissão Local de Saúde. Eles silenciam sobre os interesses dos atuais membros e tentam minimizar a existência de conflitos nas entrevistas. Para isso, utilizam linguagem objetiva, respaldada pela técnica, pela autoridade e por documentos oficiais. Em outros momentos, quando falando de cooperação entre gestão pública e membros da Comissão Local, já substituem a linguagem por uma mais subjetiva, baseada na memória, situação em que retrospectiva e perspectiva se fazem presentes.

Os membros da Comissão Local, por sua vez, constroem sentido mais a partir dos sentimentos, da promoção pessoal. Para tanto, usam uma linguagem mais subjetiva, em que é possível perceber traços da construção de identidade. Além disso, a partir dessa identificação com o serviço público, observa-se a construção de sentido de participação como objetivo institucional, demonstrando que os membros se consideram diferentes do povo - a quem deveriam representar. Isso sugere novamente o caráter de nobreza da função.

Como contribuições, permite-se ver como os sentidos construídos de participação popular marginalizam o conceito de deliberação pública (Marques, 2009). A participação passa a ser compreendida e compartilhada em um ambiente sensível, cheio de ambiguidades, como a saúde pública. Este trabalho permite ver como os relacionamentos entre atores acontecem nas organizações e como eles ordenam o mundo. É possível perceber a tônica da legitimação dos gestores a partir das ações dos Conselhos bem como a regência da ótica de mercado nas relações políticas em que se privilegia a troca e a parceria que gere benefícios, muitas vezes diluindo fronteiras entre o público e o privado. Além disso, é possível perceber nuances do não compartilhamento dos sentidos cujos atores buscam mais plausibilidade em seus argumentos do que precisão. Se não houver espaço de debate, pode-se não conseguir o engajamento da população em processos de mobilização bem como haver distorções nas concepções de políticas públicas voltadas à participação popular.

Construções de sentido não compartilhadas podem influir diretamente na elaboração, gestão e avaliação de políticas públicas de saúde. Se uma política pública é construída considerando que uma comunidade é participativa e essa proposição não refletir a visão da própria comunidade envolvida, corre-se o risco de beneficiar apenas uma parcela da população, de perceber erroneamente qual é a avaliação popular sobre a gestão, de despender bens e recursos que não serão compartilhados por toda a comunidade, entre outras questões. Vale observar as limitações deste estudo que não considerou a percepção da própria comunidade envolvida no contexto. Sugere-se, como possibilidades de pesquisa futuras, que a comunidade seja investigada, bem como o conhecimento da realidade de outros centros de saúde e seu processo de construção de sentido.

\section{Notas}

1. Agradecemos a contribuição dos avaliadores deste artigo que nos propiciaram uma reflexão acerca da consistência e coerência teórica-metodológica e o aprimoramento deste trabalho de pesquisa.

\section{Referências}

Bahia, L., Costa, N., \& Van Stralen, C. (2007). A saúde na agenda pública: convergências e lacunas nas pautas de debate e programas de trabalho das instituições governamentais e movimentos sociais. Ciência \& Saúde Coletiva, 12(sup.), 1791-1818.

Boje, D. M., Oswick, C., \& Ford G. D. (2004). Language and organization: the doing of discourse. Academy of Management Review, 29(4), 571-577.

Borges, M. L. (2010). Eventos inesperados através do entendimento teórico de Karl Weick e de Niklas Luhmann. Tese de doutorado, Universidade do Vale do Rio dos Sinos, São Leopoldo, RS, Brasil.

Brasil. Conselho Nacional de Secretários de Saúde. (2007). Atenção primária e promoção da saúde. Brasília: CONASS. 
Camargo-Borges, C., \& Mishima, S. M. (2009). A responsabilidade relacional como ferramenta útil para a participação comunitária na atenção básica. Saúde e Sociedade, 18(1), 29-41.

Carrieri, A. P., Saraiva, L. A. S., Pimentel, T. D., \& Souza-Ricardo, P. A. G. (2009). (Orgs.). Análise do discurso em estudos organizacionais. Curitiba: Juruá.

Costa, M. E. B. (2008). Grupo focal. In: J. Duarte \& A. Barros (Orgs.). Métodos e técnicas de pesquisa em comunicação (pp. 180-192). São Paulo: Atlas.

Cunha, E., \& Pinheiro, M. (2009). Conselhos nacionais: condicionantes políticos e efetividade social. In: L. Avritzer (Org.). Experiências nacionais de participação social (pp. 142-156). São Paulo: Cortez.

Czarniawska, B. (2005). Karl Weick: concepts, style and reflection. Sociological Review Monograph, 53(2), 267278.

Fairclough, N. (2010). A dialética do discurso. Teias, 11(22), 225-234.

Fairclough, N. (2001). Discurso e mudança social. Brasília: UnB.

Fiorin, J. L. (2009). Língua, discurso e política. Alea: Estudos Neolatinos, 11(1), 148-165.

Guimarães, C. P. (2012). Análise crítica do discurso: reflexões sobre contexto em van Dijk e Fairclough. Eutomia, Revista de Literatura e Linguística, 2(9), 438-457.

Klein Jr, V. H., Salm, J. F., Heidemann, F. G., \& Menegasso, M. E. (2012). Participação e coprodução em política habitacional: estudo de um programa de construção de moradias em SC. Revista de Administração Pública, 46(1), 25-47.

Kreps, G. L. (2009). Applying Weick's model of organizing to health care and health promotion: highlighting the central role of health communication. Patient Education \& Counseling, 74(3), 347-355.

Malanovicz, A. V. (2011). Contribuição do modelo de organização de Karl Weick para a compreensão teórica do processo de entendimento compartilhado entre usuários e desenvolvedores sobre as demandas de desenvolvimento de sistemas de informação. Tese de doutorado, Universidade Federal do Rio Grande do Sul, Porto Alegre, RS, Brasil.

Maravalhas, E. (2010, setembro). Aprendizagem organizacional e sensemaking na implementação de novas práticas de trabalho. Anais do Encontro Anual da Associação Nacional de Pós-Graduação e Pesquisa em Administração, Rio de Janeiro, RJ, Brasil, 34.

Marques, A. (2009). A deliberação pública e suas dimensões sociais, políticas e comunicativas. Belo Horizonte: Autêntica.

Melo, I. F. (2009). Análise do discurso e análise crítica do discurso: desdobramentos e intersecções. Revista Eletrônica de Divulgação Científica em Língua Portuguesa, Linguística e Literatura, 5(11), 1-18.

Montenegro, L. M., \& Bulgacov, Y. L. M. (2009). Construção de sentidos em práticas de um processo estratégico: um estudo comparativo em duas IES do Estado do Paraná. Anais do Encontro Anual da Associação Nacional de Pós-Graduação e Pesquisa em Administração, São Paulo, SP, Brasil, 33.

Oliveira, V. C. (2004). Comunicação, informação e participação popular nos conselhos de saúde. Saúde e Sociedade, 13(2), 56-69.

Pereira, M. C., \& Brito, M. J. (2009). A análise do discurso como prática e processo de produção de sentidos: proposta teórico-metodológica. In: A. P. Carrieri, L. A. S. Saraiva, T. D. Pimentel \& P. A. G. Souza-Ricardo (Orgs.). Análise do discurso em estudos organizacionais (pp. 53-78). Curitiba: Juruá.

Peruzzo, . C. M. K. (2007). Direito à comunicação comunitária, participação popular e cidadania. Lumina, 1, 1-29.

Pye, A. (2002). The changing power of 'explanations': directors, academics and their sensemaking from 1989 to 2000. Journal of Management Studies, 39(7), 907-925.

Rosemberg, B. (2009). Comunicação e participação em saúde. In: G. W. S. Campos, M. C. S., M. Akerman, M.; M. D. Junior \& Y. M. Carvalho (Orgs.). Tratado de saúde coletiva (2a ed.) (pp. 741-766). São Paulo/Rio de Janeiro: Hucitec/Fiocruz.

Schroeder, C. S. (2006). A interação em comunidades virtuais nas organizações e o sensemaking de Weick (1995): uma possibilidade de aproximação. Anais do Encontro Anual da Associação Nacional de Pós-Graduação e Pesquisa em Administração, Salvador, BA, Brasil, 30.

Stake, R. E. (1994). Case studies. In: N. K. Denzin \& Y. S. Lincoln (Eds.) Handbook of qualitative research (pp. 236-247). London: Sage.

Van Dijk, T. A. (1985). Introduction: dialogue as discourse and interaction. In: T. A. Van Dijk (Ed.). Handbook of discourse analysis (pp. 1-11). London: Academic Press London.

Van Dijk, T. (1997a). Discourse as social interaction: discourse studies. London: Sage. 
Van Dijk, T. (1997b). Discourse as structure and process: discourse studies. London: Sage.

Vasquez, M. L., Silva, M. R., Campos, E., Arruda, I., Diniz, A., Veras, I., \& Pereira, A. P. (2003). Participação social nos serviços de saúde: concepções de usuários e líderes comunitários em dois municípios do Nordeste do Brasil. Caderno de Saúde Pública, 19(2), 579-591.

Vieira, R. S. G., \& Fonseca, F. R. B. (2009, maio) O sensemaking como ferramenta estratégica para o desenvolvimento de redes de relacionamentos de negócios no contexto das empresas de base tecnológica. Anais do Encontro de Estudos em Estratégia, Recife, PE, Brasil, 6.

Vizeu, F., \& Bin, D. (2008). Democracia deliberativa: leitura crítica do caso CDES à luz da teoria do discurso. Revista de Administração Pública, 42(1), 83-108.

Weick, K. E. (1995). Sensemaking in organizations. Thousand Oaks: Sage.

Weick, K. E., Sutcliffe, K. M., \& Obstfeld, D. (2005). Organizing and the process of sensemaking. Organization Science, 16(4), 409-421. 